\title{
Dinamika P Tersedia, pH, C-Organik dan Serapan P Nilam (Pogostemon cablin Benth.) pada Berbagai Aras Bahan Organik dan Fosfat di Ultisols
}

\section{Soil Available P Dynamics, $p H$, OrganiC-C, and P Uptake of Patchouli (Pogostemon Cablin Benth.) at Various Dosages Of Organic Matters and Phosphate in Ultisols}

\author{
Any Kusumastuti \\ ${ }^{1)}$ Staf Pengajar D4 Jurusan Budidaya Tanaman Perkebunan, Politeknik Negeri Lampung. \\ Jln. Soekarno Hatta no 10 Rajabasa Bandar Lampung 35145 Telp. 0721703995 \\ Fax 0721 787309, E-mail any_rudi@yahoo.com
}

\begin{abstract}
The experiment was conducted at field experiment of Lampung State Polytechnic from June up to November 2012, using complete randomized block design with factorial pattern, which consists of two factors, and three replications. The first factor is organic matter (POME) dosage, consists of three dosages (without POME, 25\% POME with $75 \%$ soil, and 50\% POME with 50\% soil). The second factor is dosage of SP-36 Fertilizer (without SP-36, $1.8 \mathrm{~g}, 3.6 \mathrm{~g}$, and $5.4 \mathrm{~g} \mathrm{SP-36}$ per polybag (plant) respectively. The study aims was to determine (1) The dynamics of soil available $P$, (2) The effect of the best POME dosage for $\mathrm{pH}, \mathrm{C}$ organic and $P$ uptake, (3) The effect of the best $S P$-36 dosage for $\mathrm{pH}, \mathrm{C}$-organic and $P$ uptake, (4) The interaction between dosages of POME and SP-36 on pH, $C$-organic and $P$ uptake of plant. The observation consists of (a) Soil available $P$, (b) $\mathrm{pH}$ and $C$-organic (c) and $P$ uptake of plant. The data was analysis with variance analysis, furthermore, if the result is significance, was continued with LSD test, but soil available $P$ dynamics was presented in graphic form. The result showed that (a) Applications of POME and SP-36 increase the soil available $P$, (b) The media with 25\% POME and 50\% POME were gave the better result on $\mathrm{pH}, C$-organic and $P$ uptake by plant, (c) SP-36 fertilizer fertilizer at various doses has not been any impact on soil $\mathrm{pH}$, organic-C and $P$ uptake of plants $(d)$ There is no interaction between POME and SP-36 fertilizer on soil $\mathrm{pH}$, organic $\mathrm{C}$ and $\mathrm{P}$ uptake of plants
\end{abstract}

Keywords : P Dynamics, P Uptake of Patchouli, Pogostemon cablin, ultisols

Diterima 30-10 2013, disetujui: 02-05-2014

\section{PENDAHULUAN}

Ultisols merupakan tanah yang sudah berkembang lanjut, mempunyai sifat reaksi agak masam sampai masam, Kapasitas Tukar Kation (KTK) dan kandungan bahan organik rendah (Hardjowigeno, 1993; Darmawijaya, 1997), kandungan aluminium dan mangan tinggi sehingga 
sering mengakibatkan keracunan serta kahat fosfor, kalsium dan Molibdenum (Radjagukguk, 1991; Hakim, dkk., 1986). Secara umum pada tanah Ultisols P total tanah tinggi akan tetapi P tersedia dan kandungan bahan organik sangat rendah. Fosfor yang diberikan melalui pemupukan sebagian besar akan difiksasi oleh Al dan Fe. Sehingga hanya 10-20\% P yang diberikan ke dalam tanah dapat digunakan oleh tanaman (Foth, 1998). Pemberian pupuk P (anorganik) kedalam tanah ultisols akan menjadi lebih tersedia dan meningkatkan tanggapan tanaman terhadap P jika disertai dengan pemberian bahan organik (Lian, 1993; Adiningsih, Sofyan dan Nursyamsi, 1998). Ultisols mendominasi luasan wilayah lahan kering di Indonesia (Subagyo dkk., 2000) sehingga perlu penanganan apabila akan digunakan untuk budidaya tanaman.

POME (Palm Oil Mill Effluent) merupakan salah satu bentuk hasil akhir pabrik pengolahan buah kelapa sawit yang berupa bubur. Pada saat ini terdapat banyak hasil samping olahan sawit bersamaan dengan semakin luasnya laan budidaya kelapa sawit. untuk mengatasi penumpukan yang semakin banyak dari hasil samping pabrik kelapa sawit yang tersebar di Indonesia dan rendahnya kesuburan tanah ultisols, maka POME dapat digunakan sebagai salah satu alternatif bahan pembenah tanah berupa bahan organik, namun penelitian mengenai masalah ini belum banyak dilakukan.

Dalam usaha untuk memperbaiki kesuburan tanah pada ultisols karena kekahatan P dan kandungan bahan organik serta melimpahnya POME sebagai hasil samping pabrik pengolahan kelapa sawit perlu dicoba kombinasi pemberian bahan pembenah tanah berupa POME dan pupuk P. Dari kombinasi tersebut diharapkan sifat-sifat baik dari kedua bahan tersebut akan meningkatkan produktivitas tanah ultisols selanjutnya dapat meningkatkan $\mathrm{P}$ tersedia, $\mathrm{pH}$ tanah, C-organik dan serapan P yang tinggi pada tanaman.

Penelitian ini bertujuan untuk (1) mengetahui dinamika $\mathrm{P}$ tersedia akibat pemberian bahan organik dan pupuk fosfor di Ultisols, (2) mengetahui pengaruh aras pemberian bahan organik terbaik terhadap $\mathrm{pH}, \mathrm{C}$ organik dan serapan $\mathrm{P}$ tanaman di Ultisols, (3) mengetahui pengaruh aras pemberian pupuk fosfor terbaik terhadap $\mathrm{pH}, \mathrm{C}$-organik dan serapan $\mathrm{P}$ tanaman di Ultisols, (4) mengetahui pengaruh interaksi antara aras pemberian bahan organik dan pupuk fosfor terhadap $\mathrm{Ph}$, C-Organik dan serapan P tanaman di Ultisols.

\section{METODE}

Penelitian dilaksanakan di Politeknik Negeri Lampung dari bulam Juni sampai November 2012. Penelitian dilaksanakan dengan menggunakan Rancangan Acak Kelompok Lengkap (RAK) pola Faktorial, yang terdiri atas dua faktor perlakuan dan setiap kombinasi perlakuan diulang tiga kali. Faktor pertama adalah takaran bahan organik (POME) yang terdiri dari tiga aras (tanpa bahan organik/tanah saja, $25 \%$ bahan organik dan75\% Ultisols serta $50 \%$ bahan organik dan $50 \%$ Ultisols). Faktor kedua adalah takaran pupuk SP-36 (tanpa pupuk, pupuk fosfat 1,8 gr.tan ${ }^{-1}, 3,6$ gr.tan ${ }^{-1}, 5,4$ gr. $\left.\tan ^{-1}\right)$.

Pengambilan tanah dilakukan secara komposit pada jeluk olah $(0-20 \mathrm{~cm})$. Tanah terlebih dahulu dikeringanginkan, kemudian disaring hingga lolos mata saring $5 \mathrm{~mm}$, setelah itu ditimbang $10 \mathrm{~kg}$ untuk setiap polibag dengan ukuran $30 \times 40 \mathrm{~cm}$. Untuk keperluan analisis tanah, maka tanah yang telah lolos ayakan $5 \mathrm{~mm}$ tersebut diayak lagi dengan ayakan $2 \mathrm{~mm}$.

Bahan pembenah tanah berupa bahan organik (POME) yang sudah kering angin dihaluskan dan disaring dengan ayakan 100 mesh. POME dan pupuk SP-36, masing-masing ditimbang sesuai 
Any Kusumastuti: Dinamika P Tersedia, pH, C-Organik dan Serapan P Nilam...

dengan perlakuan. Tanah yang sudah disiapkan untuk percobaan dicampur merata dengan POME dan pupuk SP-36 sesuai dengan perlakuan. Setelah semuanya dicampur merata, dimasukkan dalam polibag dan ditambahkan air sampai kondisi kapasitas lapang, dilanjutkan inkubasi selama satu bulan. Setelah masa inkubasi, polibag diletakkan secara acak sesuai perlakuan dan siap untuk percobaan dengan tanaman.

Bibit nilam berumur 1 bulan ditanam pada media perlakuan. Pada umur dua minggu setelah tanam, dilakukan pemupukan dasar yaitu $\mathrm{N}$ berupa urea $200 \mathrm{~kg} \mathrm{ha}^{-1}$ sepertiga dosis dan $\mathrm{K}$ berupa $\mathrm{KCl}\left(200 \mathrm{~kg} \mathrm{ha}^{-1}\right.$ ) diberikan seluruhnya. Sisa pupuk N diberikan pada tiga minggu selanjutnya. Tindakan pengendalian hama penyakit dilakukan seperlunya.

Untuk melihat pengaruh penggunaan bahan organik dan pupuk fosfat maka dilakukan pengamatan : (a) analisis pendahuluan tanah dan bahan organik (POME), (b) dinamika $\mathrm{P}$ tersedia media tanam kombinasi bahan organik (POME) dan pupuk, (c) pH tanah akhir penelitian, Corganik akhir penelitian (d) analisis jaringan Tanaman (serapan P)

Hasil pengamatan dianalisis sidik ragam. Selanjutnya apabila uji $\mathrm{F}$ terdapat perbedaan nyata, maka dilanjutkan dengan uji harga rata-rata dengan uji BNT, sedangkan dinamika P tersedia disajikan dan dianalisis dalam bentuk grafik.

\section{HASIL DAN PEMBAHASAN}

\section{Sifat tanah Ultisol dan POME sebagai media tanaman}

Hasil analisis tanah Ultisols yang digunakan sebagai media tanam menunjukkan bahwa $\mathrm{pH}$ tanah dan bahan organik menunjukkan harkat agak masam, kandungan $\mathrm{P}$ tersedia dalam tanah ultisols maupun bahan organik (POME) sangat rendah yaitu 0,04 ppm dan 2,74 ppm. P total tanah rendah sedangkan dalam POME tinggi. Hal ini diduga ion $\mathrm{P}$ dalam tanah diikat oleh oksida $\mathrm{Al}$ dan Fe. Hasil Analisis Sifat Tanah dan POME disajikan dalam Tabel 1

Tabel 1. Hasil Analisis Sifat Tanah dan POME

\begin{tabular}{|c|c|c|c|c|c|}
\hline \multirow[b]{2}{*}{ No } & \multirow{2}{*}{ Sifat kimiaTanah } & \multicolumn{2}{|c|}{ Tanah (ultisols) } & \multicolumn{2}{|c|}{ Bahan organik (POME) } \\
\hline & & Nilai & Harkat & Nilai & Harkat \\
\hline 1 & $\mathrm{pH} \mathrm{H} 2 \mathrm{O}(1: 2,5)$ & 5,85 & Agak masam & 6,52 & Agak masam \\
\hline 2 & P tersedia (ppm) & 0,04 & Sangat rendah & 2,74 & Sangat rendah \\
\hline 3 & P-total (ppm) & 14,26 & Rendah & 113,39 & Sangat tinggi \\
\hline 4 & C-Organik (\%) & 1,37 & Sangat rendah & 7,59 & Sangat rendah \\
\hline 5 & $\mathrm{KTK}(\mathrm{me} / 100 \mathrm{~g})$ & 4,95 & Sangat rendah & 12,98 & Sangat rendah \\
\hline
\end{tabular}

Keterangan : Laboratorium Tanah Unila, 2012.

Tanah dengan kondisi $\mathrm{P}$ tersedia sangat tendah apabila tidak ada penambahan $\mathrm{P}$ dari luar berupa pupuk $\mathrm{P}$ dapat berakibat pertumbuhan tanaman terganggu. KTK hasil analisis juga menunjukkan hasil rendah. Hal ini mengindikasikan bahwa tanah sudah mengalami pelapukan lanjut sehingga kesuburan tanah rendah dan didukung oleh hasil analisis $\mathrm{pH}$ tanah dan $\mathrm{P}$ tersedia. Nilai KTK rendah menyebabkan kation-kation dalam tanah berupa $\mathrm{K}^{+}, \mathrm{NH}^{+}, \mathrm{Ca}^{++}$dan lain-lain mudah terlindi akibatnya tanah miskin akan unsur hara. 


\section{Dinamika P tersedia media tanah yang diberi kombinasi bahan organik (POME) dan Pupuk SP-36}

Dinamika P tersedia pada berbagai kombinasi perlakuan ditunjukkan dengan menganalisis $\mathrm{P}$ tersedia pada setiap bulan. Hasil analisis $\mathrm{P}$ tersedia pada setiap bulan setelah tanam sampai bulan ke-empat pada setiap perlakuan disajikan pada Gambar 1.

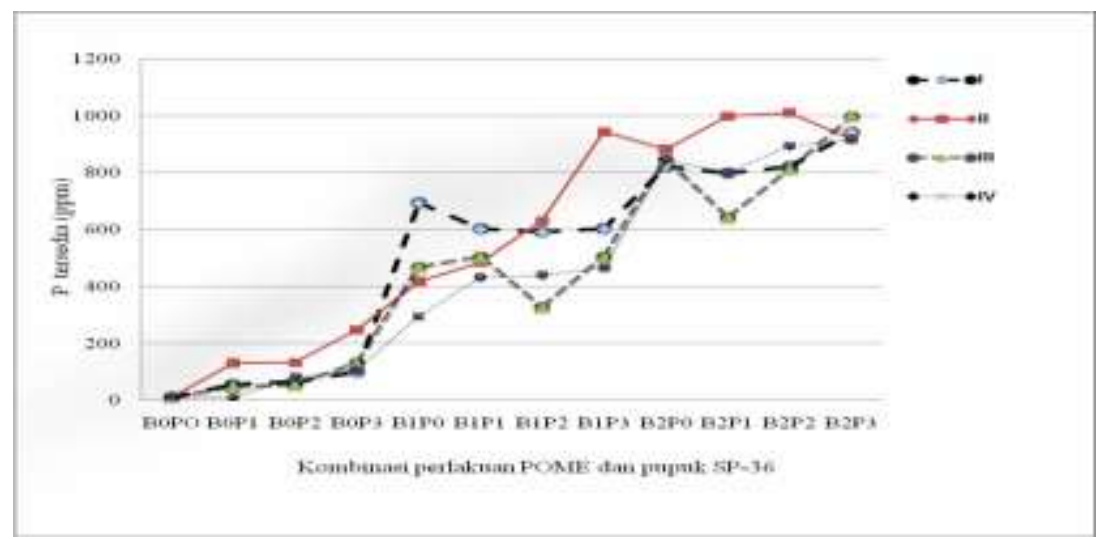

Gambar 1. Dinamika P tersedia pada berbagai kombinasi perlakuan pemberian bahan organik (POME) dan Pupuk SP-36 pada Media Tanaman pada Ultisols

Keterangan : (a) B0P0 $=$ tanpa POME dan tanpa pupuk; B0P1 $=$ tanpa POME dan pupuk takaran $1,8 \mathrm{~g} \mathrm{tan}^{-1}$, $\mathrm{B} 0 \mathrm{P} 2=$ pupuk takaran $3,6 \mathrm{~g} \tan ^{-1}, \mathrm{~B} 0 \mathrm{P} 3=$ pupuk takaran $5,4 \mathrm{~g} \mathrm{tan}^{-1}, \mathrm{~B} 1 \mathrm{P} 0=$ POME $25 \%$ dan tanpa pupuk, B1P1 = POME 25\% dan pupuk takaran 1,8g $\tan ^{-1} ; \mathrm{B} 1 \mathrm{P} 2=\mathrm{POME} 25 \%$ dan pupuk takaran 3,6g $\tan ^{-1}, \mathrm{~B} 1 \mathrm{P} 3=$ POME $25 \%$ dan pupuk takaran $15,4 \mathrm{~g} \mathrm{tan}^{-1}, \mathrm{~B} 2 \mathrm{P0}=$ POME 50\% dan tanpa pupuk; B2P1 = POME 50\% dan pupuk takaran 1,8g $\tan ^{-1 ;} \mathrm{B} 2 \mathrm{P} 2=$ POME 50\% dan pupuk takaran 3,6g $\tan ^{-1,} \mathrm{~B} 2 \mathrm{P} 3=$ POME 50\% dan pupuk takaran 15,4 $\mathrm{g} \mathrm{tan}^{-1}$

(b) I = satu bulan, II = dua bulan, III = tiga bulan dan IV = empat bulan

Gambar 1 menunjukkan $\mathrm{P}$ tersedia mengalami kenaikkan dengan adanya penambahan kombinasi POME dan pupuk SP-36. Pada perlakuan tanpa pemberian POME dan pupuk SP-36 menunjukkan hasil lebih rendah pada setiap bulan pengamatan (dari bulan pertama sampai bulan keempat).

$\mathrm{P}$ tersedia pada perlakuan tanpa pemberian POME dengan pemberian berbagai takaran pupuk menunjukkan hasil lebih rendah dibandingkan dengan media yang diberi POME 25\% maupun 50\%. Hal ini diduga pemberian POME mampu meningkatkan KPK tanah sehinggga $\mathrm{P}$ yang berasal dari pupuk maupun $\mathrm{P}$ tanah yang tidak tersedia dapat menjadi tersedia. Unsur hara $\mathrm{P}$ pada tanah ultisols akan terikat oleh $\mathrm{Al}$ dan Fe dalam bentuk hidroksi fosfat sehingga akan membentuk senyawa tidak larut, yang mengakibatkan P tidak tersedia bagi tanaman (Bohn et al., 1979; Hardjowigeno, 1993). Al dalam larutan tanah menjadi tidak aktif apabila berinteraksi dengan bahan humat sehingga penyematan fosfat dapat dikurangi, dengan demikian ketersediaan P dalam tanah meningkat (Stevenson, 1994). Gugus-gugus fungsi asam organik berperan dalam pemblokiran permukaan aluminium hidroksida yang reaktif terhadap fosfat oleh gugus spesifik anoin organik, sehingga dapat meniadakan pengaruh pengikatan permukaan spesifik terhadap fosfat (Moshi et al., 1974). Pada bulan ketiga dan keempat $\mathrm{P}$ tersedia mengalami penurunan dibandingkan pada bulan pertama dan kedua, hal ini diduga bahwa $\mathrm{P}$ tersedia dalam larutan tanah diabsorpsi oleh tanaman, sehingga secara perlahan keberadaan $\mathrm{P}$ tanah menurun. 
Any Kusumastuti: Dinamika P Tersedia, pH, C-Organik dan Serapan P Nilam...

\section{Pengaruh Pemberian POME dan Pupuk SP-36 Terhadap pH tanah dan C-organik}

Analisis sidik ragam menunjukkan bahwa pemberian bahan organik (POME) berpengaruh nyata terhadap $\mathrm{pH}$ tanah, sedangkan pemberian pupuk Fosfat dan interaksi antara pemberian POME dan pupuk fosfat tidak berpengaruh nyata terhadap $\mathrm{pH}$ tanah (Tabel 2)

Tabel 2. PH tanah dan C-organik pada berbagai Aras Pemberian POME dan Pupuk SP-36 di ultisols

\begin{tabular}{cccc}
\hline & Perlakuan & $\mathrm{pH}$ tanah $(\mathrm{H} 20)$ & C-organik $(\%)$ \\
\hline POME & 0 & $5,52 \mathrm{~b}$ & $1,49 \mathrm{c}$ \\
$(\%)$ & 25 & $5,97 \mathrm{a}$ & $2,18 \mathrm{~b}$ \\
& 50 & $6,11 \mathrm{a}$ & $3,19 \mathrm{a}$ \\
\hline Pupuk SP-36 $_{\left(\mathrm{g} \mathrm{tan}^{-1}\right)}$ & 0 & $5,70 \mathrm{a}$ & $2,24 \mathrm{a}$ \\
& 1,8 & $5,89 \mathrm{a}$ & $2,22 \mathrm{a}$ \\
& 3,6 & $5,91 \mathrm{a}$ & $2,42 \mathrm{a}$ \\
& 5,4 & $5,96 \mathrm{a}$ & $2,28 \mathrm{a}$ \\
\hline
\end{tabular}

Keterangan: Rerata yang diikuti oleh huruf yang sama pada kolom yang sama menunjukkan tidak berbeda nyata dengan uji BNT pada taraf 5\%.

Pengaruh pemberian bahan organik (POME) terhadap kenaikkan $\mathrm{pH}$ tanah diduga disebabkan adanya mineralisasi bahan organik dan pelepasan kation-kation basa ke dalam larutan tanah (Hue, 1992). Selain itu, hasil dekomposisi bahan organik akan dihasilkan asam-asam organik, melalui gugus-gugus fungsional asam organik yang dapat bereaksi dengan $\mathrm{Al}$ dalam mineral tanah membentuk Al-organo kompleks yang bersifat tidak larut. Selanjutnya, akan terbentuk Al-organo chelate atau organo kompleks melalui interaksi antara gugus fungsi asam asam organik terjadi dalam bentuk antara lain reaksi kompleks, kelasi dan lain-lain (Barlett dan Rego, 1972) sehingga menurunkan konsentrasi $\mathrm{Al}$ dalam larutan tanah.

Pengaruh pemberian pupuk fosfat (SP-36) terhadap $\mathrm{pH}$ tanah menunjukkan hasil yang tidak berbeda nyata. Larutan asam fosfat yang keluar dari butiran pupuk SP-36 mempunyai pH yang sangat masam (Sanchez, 1976). Pada pH rendah tersebut mengakibatkan akan melarutkan Al, $\mathrm{Fe}, \mathrm{K}$ dan $\mathrm{Mg}$ dalam partikel tanah. Namun demikian, penurunan $\mathrm{pH}$ tersebut akan segera disangga oleh tanah (Bohl, et al., 1979). Mekanisme penyanggaan berlanggung apabila pH meningkat akan terbentuk $\mathrm{Al}(\mathrm{OH})_{3}$ dengan melepaskan $\mathrm{H}^{+}$dan apabila $\mathrm{pH}$ turun maka $\mathrm{Al}^{3+} .6 \mathrm{H} 2 \mathrm{O}$ akan terbentuk dengan mengikat kembali $\mathrm{H}^{+}$(Sutanto, 1995). Analisis sidik ragam menunjukkan bahwa pemberian bahan organik (POME) berpengaruh nyata terhadap C-organik, sedangkan pemberian pupuk Fosfat dan interaksi antara pemberian POME dan pupuk fosfat tidak berpengaruh nyata terhadap C-orgnik (Tabel 2).

Pemberian bahan organik 50\% dan 25\% tidak berpengaruh nyata terhadap C organik akan tetapi berpengaruh terhadap $\mathrm{C}$ organik tanah pada tanah yang tidak diberi bahan organik (POME). POME merupakan suspensi koloid yang mengandung bahan-bahan organik terlarut dan bahan padatan yang tinggi, dengan demikian apabila diaplikasikan ke tanah dengan kandungan bahan organik yang rendah, maka kandungan bahan organik tanah tersebut akan bertambah seiring dengan meningkatnya dosis POME Seiring dengan tingginya KPK pada POME (Tabel 1) maka semakin tinggi $\mathrm{C}$ organik dalam tanah.

Faktor perlakuan pupuk Fosfat dalam penelitian ini tidak berpengaruh terhadap C-organik. Pemberian SP-36 belum mampu meningkatkan pH tanah. Diduga kondisi yang lebih baik bagi perkembangan mikroorganisme tanah belum "tercipta", akibatnya populasi mikroorganisme yang menguraikan bahan organik belum mampu meningkatkan C-organik. 


\section{Pengaruh Pemberian POME dan Pupuk SP-36 Terhadap Serapan P tanaman}

Dari hasil analisis sidik ragam menunjukkan bahwa pemberian POME berbeda nyata terhadap serapan $\mathrm{P}$ tanaman, sedangkan pemberian pupuk SP-36 maupun interaksi antara pemberian POME dan pupuP-36 menunjukkan hasil yang tidak berbeda nyata terhadap serapan $\mathrm{P}$ tanaman.

Tabel 4. Serapan P tanaman pada berbagai Aras Pemberian POME dan Pupuk SP-36 di ultisols

\begin{tabular}{ccc}
\hline & Perlakuan & Serapan P tanaman \\
\hline POME & 0 & $0,1438 \mathrm{c}$ \\
$(\%)$ & 25 & $0,2700 \mathrm{~b}$ \\
& 50 & $0,3287 \mathrm{a}$ \\
\hline Pupuk SP-36 & 0 & $0,2233 \mathrm{a}$ \\
$\left(\mathrm{g} \mathrm{tan}^{-1}\right)$ & 1,8 & $0,2633 \mathrm{a}$ \\
& 3,6 & $0,2450 \mathrm{a}$ \\
& 5,4 & $0,2458 \mathrm{a}$
\end{tabular}

Keterangan: Rerata yang diikuti oleh huruf yang sama pada kolom yang sama menunjukkan tidak berbeda nyata dengan uji BNT pada taraf 5\%.

Pengaruh pemberian POME pada serapan $\mathrm{P}$ tanaman adalah semakin tinggi takaran POME (50\%) menunjukkan hasil tertinggi $(0,3287 \mathrm{ppm})$ sedangkan POME (25\%) serapan lebih rendah $(0,2700 \mathrm{ppm})$ dilanjutkan hasil terendah adalah tanpa pemberian POME. Semakin tinggi $\mathrm{P}$ tersedia dalam tanah maka semakin besar serapan P tanaman akibat pemberian POME. Hasil penelitian Ferisman (1992) menunjukkan bahwa pemberian limbah kelapa sawit pada tanah PMK berpengaruh meningkatkan $\mathrm{P}$ tersedia tanah $(11,2-24,9 \%)$; menurunkan $\mathrm{P}$ total tanah $(6,5-$ $8,2 \%)$; meningkatkan konsentrasi P $(4,9-15,1 \%)$; meningkatkan serapan $\mathrm{P}$ oleh tanaman $(6,8-$ $27 \%)$.

Secara umum dari hasil pengamatan terhadap semua parameter (dimanika $\mathrm{P}$ tanah, tinggi tanaman, berat kering tajuk dan akar serta serapan $\mathrm{P}$ tanaman) ternyata POME memberikan pengaruh yang lebih baik. Pemberian POME sampai dengan 50\% menunjukkan hasil terbaik. Hal ini dapat dikatakan bahwa POME sebagai hasil samping pengolahan minyak sawit mempunyai potensi untuk dikembangkan menjadi bahan pembenah

\section{KESIMPULAN}

Dinamika $\mathrm{P}$ tersedia menujukkan Pemberian POME dan SP 36 mampu menaikkan $\mathrm{P}$ tersedia dalam tanah. Media dengan pemberian POME pada takaran 25\% dan 50\% memberikan hasil lebih baik dibandingkan dengan tanpa pemberian POME terhadap meningkatkan $\mathrm{pH}\left(\mathrm{H}_{2} \mathrm{O}\right), \mathrm{C}$ organik maupun serapan $\mathrm{P}$ tanaman. Pupuk SP-36 pada berbagai takaran belum mampu meningkatkan $\mathrm{pH}\left(\mathrm{H}_{2} \mathrm{O}\right), \mathrm{C}$ organik maupun serapan $\mathrm{P}$ tanaman. Tidak terdapat interaksi antara POME dan pupuk SP-36 terhadap $\mathrm{pH}\left(\mathrm{H}_{2} \mathrm{O}\right)$, C organik maupun serapan $\mathrm{P}$ tanaman.

\section{DAFTAR PUSTAKA}

Adiningsih, J. S., A. Sofyan, D. Nursyamsi. 1998. Lahan Sawah dan Pengelolaannya dalam Sumberdaya Lahan Indonesia dan Pengelolaannya. Pusat Penelitian Tanah dan 
Any Kusumastuti: Dinamika P Tersedia, pH, C-Organik dan Serapan P Nilam...

Agroklimat. Badan Penelitian dan Pengembangan Pertanian. Departemen Pertanian. Bogor. $165-196$

Barlett, R.J. and D.C. Riego. 1972. Effect of Chelasion on the Toxicity in Subsoils. Soil Sci.Soc. of Am. J. 50:28-34

Bohn, H.L., B.L.McNeal and G.A.O'Connor. 1979. Soil Chemistry. John and Wiley \& Sons, Inc., New York. 329 hal

Darmawijaya, M. Isa. 1992. Klasifikasi Tanah, Dasar Teori Bagi Peneliti Tanah dan Pelaksana Pertanian di Indonesia. Gadjah Mada University Press. Yogyakarta.

Ferisman, T. 1992. Kajian Pengaruh Pemberian Limbah Kelapa Sawit, Kapur dan Pupuk P terhadap Pasokan P dan Al dalam tanah serta Serapannya oleh Tanaman Pada Podsolik Merah Kuning. Tesis Program Pacsa Sarjana Ilmu-ilmu Pertanian. UGM. Yogyakarta.

Foth, H.D. 1998. Dasar-dasar Ilmu Tanah. Terjemahan. Gadjah Mada University Press. Yogyakarta. 762 hal.

Hakim, M.Y. Nyakpa, AM Lubis, S.G. Nugroho, R. Soul, M.A. Diha, Go Ban Hong dan H.H. Bailey. 1986. Dasar-dasar Ilmu Tanah. Universitas Lampung.

Hardjowigeno, S. 1993. Klasifikasi Tanah dan Pedogenesis. Edisi Pertama. Akademika Presindo. Jakarta.

Hue, N.V. 1990. Interaction of $\mathrm{Ca}\left(\mathrm{H}_{2} \mathrm{PO}_{4}\right)$ Applied to An Oxisol and Previous Slude Amandement: Soil and Crop Response. Commun. Soil Sci. Plant Anal. 21:61-73

Lian, S. 1993. Use of Chemichal Fertilizer With Organic Manure in Rice Production. Food \& Fertilizer Technology Center Extention. Bull, No. 315. Taipeh. Taiwan.

Moshi, A.O., A. Wild, and D.J. Greenland. 1974. Effecf of Organic Matter on the Charge and Phospat Adsorption Characteristicts of Kikuyu Red Clay from Kenya. Geoderma 11:275285

Radjagukguk, B. 1993. Masalah Pengapuran Tanah Masam di Indonesia. Buletin Fakultas Pertanian N0. 18. Universitas Gadjah Mada Yogyakarta.

Sanchez, P.A., R.M. Miller. 1986. Organic Matter and Soil Fertility Management for Acid Soils of the Tropic. Trans. Act.. 13th. Congr. Inst. Soc. Of Soil Sci. Hamburg. 609-625 pp.

Sutanto, R. 1995. Pedogenesis. Jurusan Ilmu Tanah. Fakultas Pertanian Universitas Gadjah Mada. Yogyakarta.

Stevenson, J. 1986. Humus Chemistry; Genesis, Composition, Reactions. Second Edition. John Willey and Sons, Inc New York. 496 ha

Subagyo, H., N. Suharta, Agus B. Siswanto. 2000. Tanah-tanah Pertanian di Indonesia dalam Sumberdaya Lahan Indonesia dan Pengelolaannya. Pusat Penelitian Tanah dan Agroklimat. Badan Penelitian dan Pengembangan Pertanian. Departemen Pertanian. Bogor. 21-65.

Sutedjo. 2008. Pupuk dan Cara Pemupukan. Rineka Cipta. Jakarta 